\title{
Erratum to: $r t f A$, a putative RNA-Pol II transcription elongation factor gene, is necessary for normal morphological and chemical development in Aspergillus flavus
}

\author{
Jessica M. Lohmar ${ }^{1}$. Pamela Y. Harris-Coward ${ }^{2}$. Jeffrey W. Cary ${ }^{2}$. \\ Sourabh Dhingra ${ }^{1}$ - Ana M. Calvo ${ }^{1}$
}

Published online: 26 April 2016

(C) Springer-Verlag Berlin Heidelberg 2016

Erratum to: Appl Microbiol Biotechnol (2016)

DOI 10.1007/s00253-016-7418-7

The original version of this article inadvertently contained mistakes. The title should read: $\boldsymbol{r} \boldsymbol{t} \boldsymbol{A} \boldsymbol{A}$, a putative RNA-Pol II transcription elongation factor gene, is necessary for normal morphological and chemical development in Aspergillus flavus. Also "RtfA" should be "rtfA" in every instance throughout this article.

The online version of the original article can be found at http://dx.doi.org/ 10.1007/s00253-016-7418-7.

Ana M. Calvo

amcalvo@niu.edu

1 Department of Biological Sciences, Northern Illinois University, 155 , Castle Dr., Dekalb, IL 60115, USA

2 Food and Feed Safety Research Unit, USDA/ARS, Southern Regional Research Center, New Orleans, LA 70124, USA 